\title{
Increased circulating levels of angiotensin-(1-7) in severely ill COVID-19 patients
}

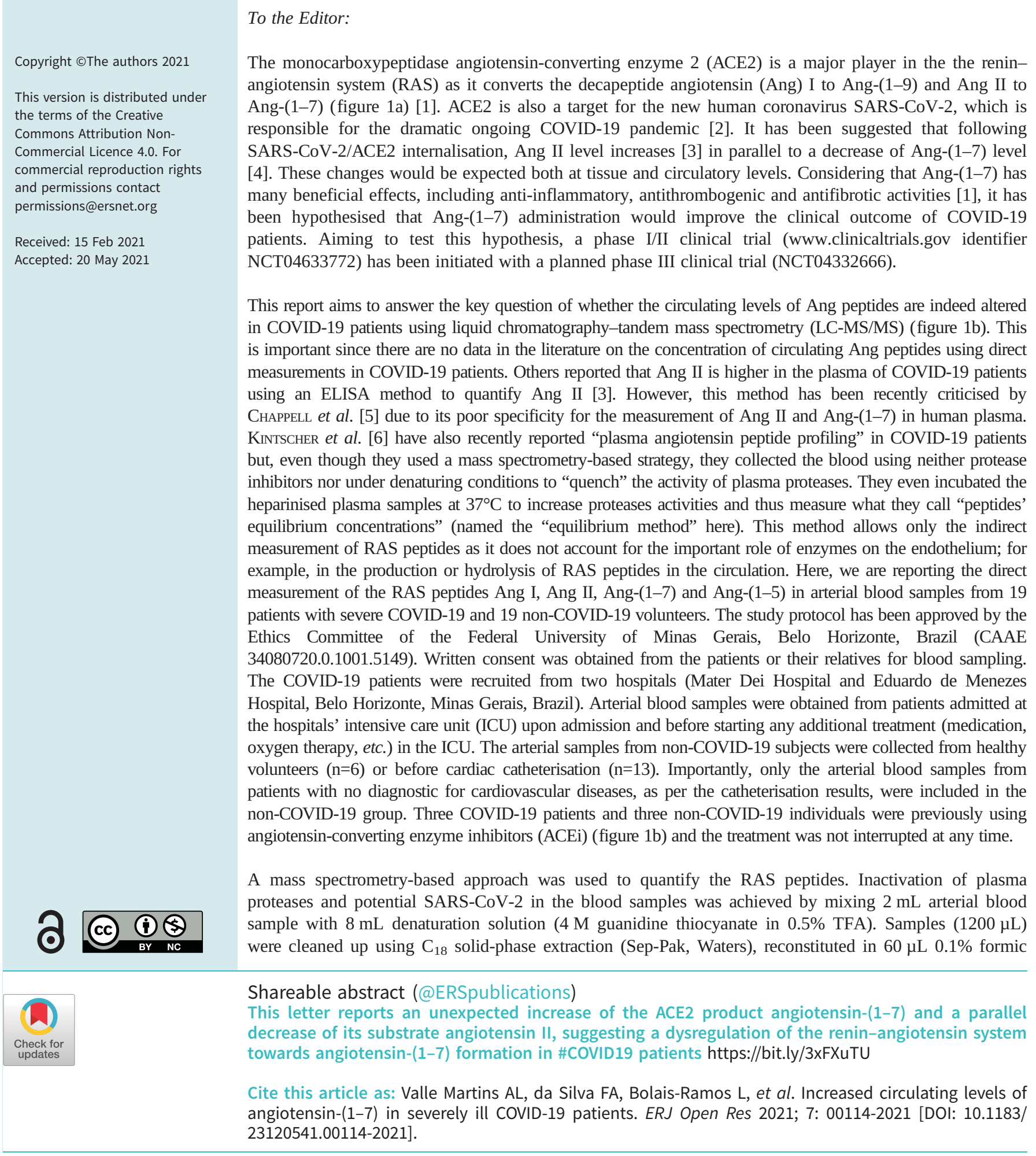


a)

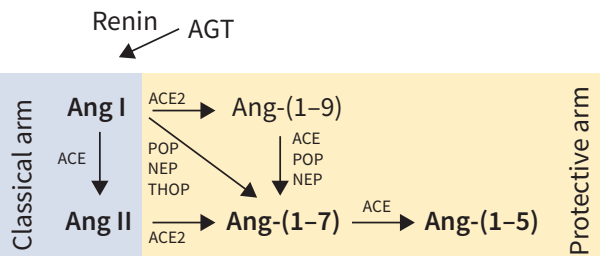

c)

Inactivation of SARS-CoV-2 and plasma proteases

( $8 \mathrm{~mL}$ of $4 \mathrm{M}$ guanidine thiocyante $+0.5 \% \mathrm{TFA}$ )

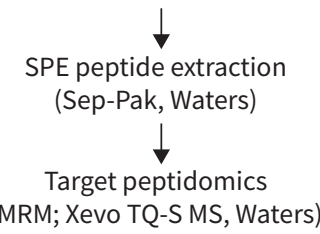

b)

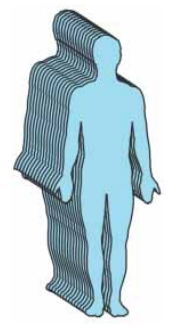

Males
nCOV

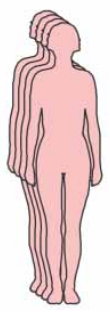

Females
COV

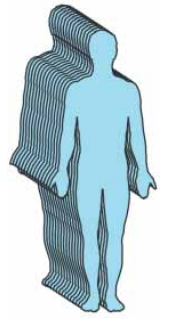

Males

14

$56 \pm 3$

3

4

$11.2 \pm 0.9$

\#NA
Symptom outbreak (days),
mean \pm SEM

\#NA
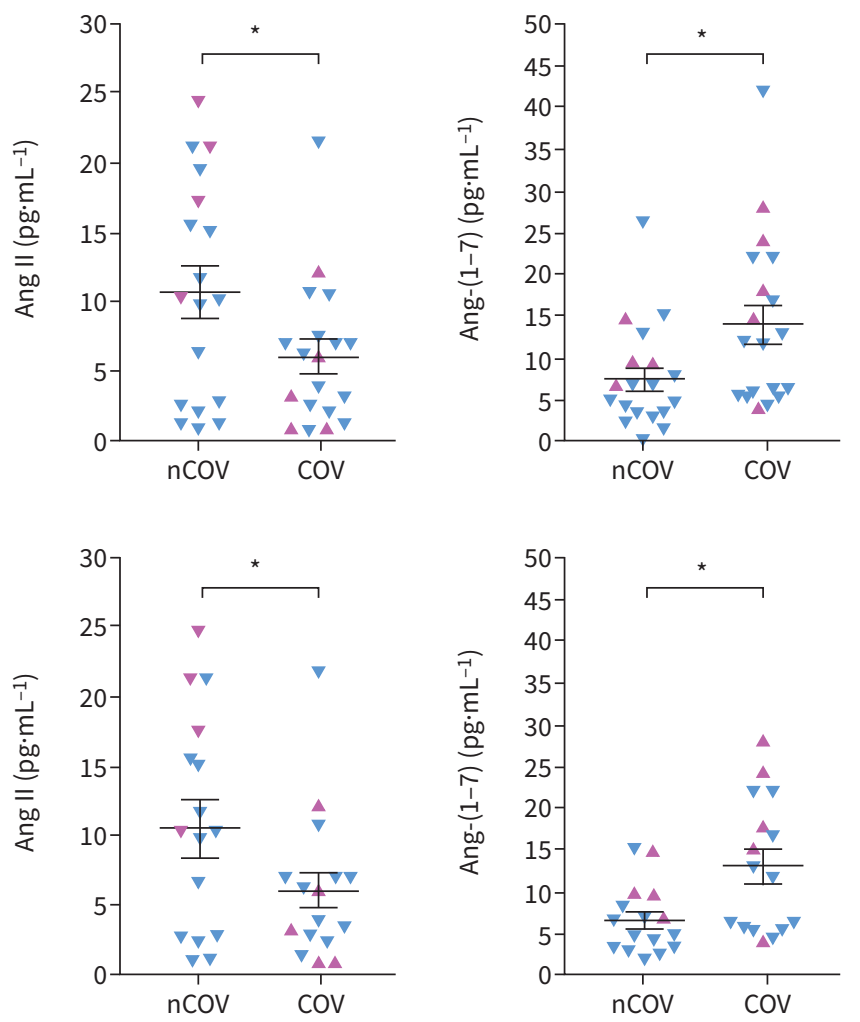

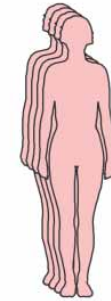

Females

5

$49 \pm 6$

0

4

$13.0 \pm 0.7$
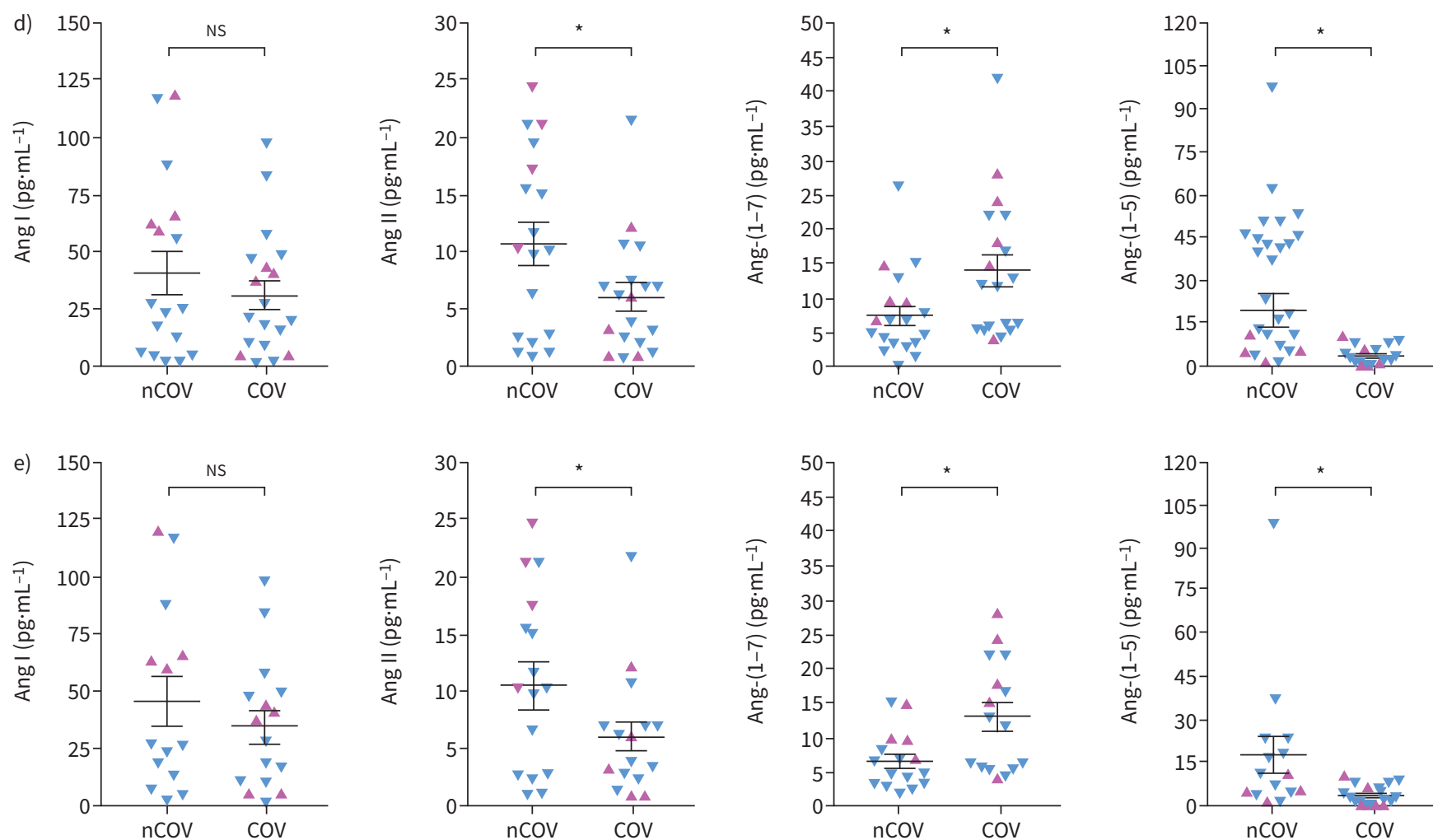

FIGURE 1 Circulating renin-angiotensin peptides in SARS-CoV-2 infection. a) A noncomprehensive view of the formation of the peptides from the renin-angiotensin system (RAS). Peptides measured in this study are in bold. b) Epidemiological parameters of the subjects included in this study (COVID-19 patients (COV) and non-COVID-19 volunteers (nCOV)). c) A simplified schematic view of the methodology employed to quantify the selected peptides from the RAS. d) Arterial blood concentration of the selected RAS peptides (angiotensin (Ang) I, Ang II, Ang-(1-7) and Ang-(1-5)) from COV and nCOV. e) Arterial blood concentration of the RAS peptides excluding individuals under angiotensin-converting enzyme inhibitor (ACEi) treatment. Blue symbols: men; pink symbols: women. Parametric t-test was used for the statistical analyses. AGT: angiotensinogen; ACE: angiotensin-converting enzyme; POP: prolyloligopeptidase; NEP: neutral endopeptidase; THOP: thimet oligopeptidase; ARB: angiotensin II receptor antagonist; \#NA: not applicable; TFA: trifluoroacetic acid; SPE: solid-phase extraction; MRM: multiple reaction monitoring. ${ }^{*}$ : $p<0.05$. 
acid (concentration factor 20×) and analysed by LC-MS/MS (Xevo TQ-S, Waters) using the multiple reaction monitoring mode (figure 1c). The calibration curve was obtained using a stock solution containing synthetic peptides (Bachem) of all RAS peptides used in this study. The applied calibration curve model $(y=a x+b)$ proved accurate over the concentration range from 10 to $1000 \mathrm{pg} \cdot \mathrm{mL}^{-1}(\mathrm{r}=0.997)$. The limit of quantitation, and inter- and intravariability of this method have been previously reported [7]. Data are presented as mean \pm SEM and the parametric t-test was used for the statistical analyses.

Arterial concentrations of the Ang peptides are shown in figure 1d. In COVID-19 patients, the arterial concentration of Ang II (6.03 \pm 1.18 versus $10.7 \pm 1.87 \mathrm{pg} \cdot \mathrm{mL}^{-1}$; $\left.\mathrm{p}=0.0381\right)$ and Ang-(1-5) (3.43 \pm 0.75 versus $\left.19.3 \pm 5.80 \mathrm{pg} \cdot \mathrm{mL}^{-1} ; \mathrm{p}=0.0084\right)$ were significantly lower than in the non-COVID-19 volunteers. Surprisingly, the blood levels of Ang-(1-7) were significantly higher in COVID-19 patients (14.0 \pm 2.32 versus $\left.7.49 \pm 1.42 \mathrm{pg} \cdot \mathrm{mL}^{-1} ; \mathrm{p}=0.0214\right)$. No significant difference was observed for Ang I (31.2 \pm 6.23 versus $\left.40.8 \pm 9.54 \mathrm{pg} \cdot \mathrm{mL}^{-1} ; \mathrm{p}=0.3959\right)$. ACEi therapy did not significantly change the observed results, as shown by the calculated values excluding the data from individuals under ACEi treatment (figure 1e): Ang I $34.5 \pm 7.07$ versus $45.2 \pm 10.8 \mathrm{pg} \cdot \mathrm{mL}^{-1}$, $\mathrm{p}=0.4023$; Ang II $6.00 \pm 1.33$ versus 11.2 $\pm 2.07, \mathrm{p}=0.0407$; Ang-(1-7) $12.9 \pm 2.02$ versus $6.47 \pm 1.03 \mathrm{pg} \cdot \mathrm{mL}^{-1}, \mathrm{p}=0.0080$; Ang-(1-5) $3.75 \pm 0.86$ versus $17.5 \pm 6.29 \mathrm{pg} \cdot \mathrm{mL}^{-1}$, $\mathrm{p}=0.0330$.

Although we did not measure the tissular levels of RAS peptides, our findings contrast with the initial hypothesis that the interaction of SARS-CoV-2 with ACE2 would result in higher Ang II and lower Ang-(1-7) levels compared to non-COVID-19 subjects [4]. Recent studies using the equilibrium method to measure the ACE2 activity [8, 9] are in line with the results presented here, as they reported higher Ang-(1-7) and lower Ang II plasma levels in severe COVID-19. For general clinical studies including nonsevere COVID-19 patients, it seems that all circulating RAS peptides are reduced due to decreased activity of renin [10]. The role of ACE2 in the observed results is questionable as previous studies suggested that one of the main routes to produce Ang-(1-7) in the circulation is by ACE2-independent pathways [11, 12]. The observed significant decrease of Ang II and increase of Ang-(1-7) arterial levels in severe COVID-19 patients (figure 1d) is probably due to a direct dysregulation of RAS pathways in COVID-19 rather than a direct consequence of ACEi usage (figure 1e). The Ang-(1-7)/Ang II ratio, which is an estimation of Ang II $\rightarrow$ Ang-(1-7) conversion, was three-fold higher in COVID-19 patients $(2.79 \pm 0.682$ versus $0.878 \pm 0.201$; $\mathrm{p}=0.0141)$, which may suggest an increased ACE2 or other Ang-(1-7)-forming activity in COVID-19. Increased soluble ACE2 in severe COVID-19 patients have been recently reported [9, 13, 14]. ReINDL-SCHWAighofER et al. [9] reported that ACE2 level increased over the course of the disease, reaching its maximum peak after $~ 10$ days of hospitalisation. Increased ACE2 correlated with increased Ang-(1-7) and decreased Ang II levels [9], suggesting its important role in controlling the circulating RAS peptides in severe COVID-19.

In contrast to a previous report [3], we observed a significant reduction of Ang II concentration in COVID-19 patients, which may add more data against the reliability of ELISA to measure Ang II in human plasma [5]. The Ang II/Ang I ratio was not significantly altered in the COVID-19 patients $(0.205 \pm 0.0322$ versus $0.292 \pm 0.0517$; $\mathrm{p}=0.1518$ ), which may suggest that ACE activity is not altered in COVID-19. Unfortunately, we were unable to perform direct measurements of enzymatic activities in this study due to the denaturating conditions that we used to collect the samples, but our estimation of increased ACE2 activity in severe COVID-19 blood samples is in line with previous reports $[9,14]$. The remaining question to be answered, though, is whether the observed increased Ang-(1-7) and decreased Ang II levels are a direct effect of SARS-CoV-2 or a consequence of inflammation due to the infection that triggers Ang-(1-7) synthesis via Ang II metabolisation.

Limitations of our study includes the small cohort included ( $\mathrm{n}=19$ for each group) and the lack of direct activity measurements of the RAS-related enzymes. Nonetheless, this is the first report of the direct measurement of RAS peptides in the arterial circulation of severe COVID-19 patients. Although future studies are obviously necessary to better understand the effects of this disease on RAS pathways, our data provide new insights for the interpretation and planning of future therapies to modulate the RAS in the context of COVID-19.

Ana Luiza Valle Martins ${ }^{1,2,6}$, Filipe Alex da Silva ${ }^{1,6}$, Lucas Bolais-Ramos ${ }^{1,6}$, Gisele Capanema de Oliveira ${ }^{1}$, Renata Cunha Ribeiro ${ }^{1}$, Danilo Augusto Alves Pereira ${ }^{1,3}$, Filippo Annoni ${ }^{4}$, Mirella Monique Lana Diniz ${ }^{1}$, Thuanny Granato Fonseca Silva ${ }^{1}$, Bruna Zivianni ${ }^{5}$, Alexandre Carvalho Cardoso ${ }^{1}$, Juliana Carvalho Martins ${ }^{5}$, Daisy Motta-Santos $\oplus^{1}$, Maria José Campagnole-Santos $\mathbb{1}^{1}$, Fabio Silvio Taccone ${ }^{4}$, Thiago Verano-Braga (1) ${ }^{1}$ and Robson Augusto Souza Santos $\mathbb{1}^{1}$ 
${ }^{1}$ National Institute of Science and Technology in Nano Biopharmaceutics (INCT-NanoBiofar) Laboratory of Hypertension, Institute of Biological Sciences, Federal University of Minas Gerais, Belo Horizonte, Brazil. ${ }^{2}$ Hospital Mater Dei, Intensive Care Unit, Belo Horizonte, Brazil. ${ }^{3}$ Waters Corporation, São Paulo, Brazil. ${ }^{4}$ Dept of Intensive Care, Hôpital Erasme, Université Libre de Bruxelles (ULB), Brussels, Belgium. ${ }^{5}$ Fundação Hospitalar do Estado de Minas Gerais - FHEMIG, Belo Horizonte, Brazil. ${ }^{6}$ These authors contributed equally.

Corresponding author: Robson Augusto Souza Santos (robsonsant@gmail.com)

Ethics statement: The study protocol has been approved by the Ethics Committee of the Federal University of Minas Gerais, Belo Horizonte, Brazil (CAAE 34080720.0.1001.5149). Written consent was obtained from the patients or their relatives for blood sampling.

Conflict of interest: A.L. Valle Martins reports a patent pending (BR1020210009950). F.A. da Silva has nothing to disclose. L. Bolais-Ramos has nothing to disclose. G.C. de Oliveira has nothing to disclose. R.C. Ribeiro has nothing to disclose. D.A.A. Pereira has nothing to disclose. F. Annoni has nothing to disclose. M.M.L. Diniz has nothing to disclose. T.G.F. Silva has nothing to disclose. B. Ziviani has nothing to disclose. A.C. Cardoso has nothing to disclose. J.C. Martins has nothing to disclose. D. Motta-Santos has nothing to disclose. M.J. Campagnole-Santos has nothing to disclose. F.S. Taccone has nothing to disclose. T. Verano-Braga has nothing to disclose. R.A.S. Santos reports patents planned.

Support statement: This work was supported by the Research Support Foundation of the State of Minas Gerais (FAPEMIG), grant number APQ-00325-20, and Angitec. M.J. Campagnole-Santos, T. Verano-Braga and R.A. Souza Santos also acknowledge the National Council for Scientific and Technological Development (CNPq) for the personal support (\#306962/2019-5, \# 309122/2019-8 and \#310515/2015-7, respectively).

\section{References}

1 Santos RAS, Sampaio WO, Alzamora AC, et al. The ACE2/angiotensin-(1-7)/MAS axis of the renin-angiotensin system: focus on angiotensin-(1-7). Physiol Rev 2018: 98: 505-553.

2 Hoffmann M, Kleine-Weber H, Schroeder S, et al. SARS-CoV-2 cell entry depends on ACE2 and TMPRSS2 and is blocked by a clinically proven protease inhibitor. Cell 2020: 181: 271-280.

3 Liu Y, Yang Y, Zhang C, et al. Clinical and biochemical indexes from 2019-nCoV infected patients linked to viral loads and lung injury. Sci China Life Sci 2020: 63: 364-374.

4 Peiro C, Moncada S. Substituting angiotensin-(1-7) to prevent lung damage in SARS-CoV-2 infection? Circulation 2020: 141: 1665-1666.

5 Chappell MC, Pirro NT, South AM, et al. Concerns on the specificity of commercial ELISAs for the measurement of angiotensin-(1-7) and angiotensin II in human plasma. Hypertension 2021; 77: e29-e31.

6 Kintscher U, Slagman A, Domenig $O$, et al. Plasma angiotensin peptide profiling and ACE (angiotensin-converting enzyme)-2 activity in COVID-19 patients treated with pharmacological blockers of the renin-angiotensin system. Hypertension 2020: 76: e34-e36.

7 Paquette K, Fernandes RO, Xie LF, et al. Kidney size, renal function, Ang (angiotensin) peptides, and blood pressure in young adults born preterm. Hypertension 2018: 72: 918-928.

8 van Lier D, Kox M, Santos K, et al. Increased blood angiotensin converting enzyme 2 activity in critically ill COVID-19 patients. ERJ Open Res 2021; 7: 00848-2020.

9 Reindl-Schwaighofer R, Hodlmoser S, Eskandary F, et al. Angiotensin-converting enzyme 2 (ACE2) elevation in severe COVID-19. Am J Respir Crit Care Med 2021; 203: 1191-1196.

10 Kutz A, Conen A, Gregoriano C, et al. Renin-angiotensin-aldosterone system peptide profiles in patients with COVID-19. Eur J Endocrinol 2021: 184: 543-552.

11 Serfozo P, Wysocki J, Gulua G, et al. Ang II (angiotensin II) conversion to angiotensin-(1-7) in the circulation is POP (prolyloligopeptidase)-dependent and ACE2 (angiotensin-converting enzyme 2)-independent. Hypertension 2020: 75: 173-182.

12 Santos RA, Brosnihan KB, Jacobsen DW, et al. Production of angiotensin-(1-7) by human vascular endothelium. Hypertension 1992: 19: Suppl. 2, II56-II61.

13 Burns $\mathrm{K}$, Cheng $\mathrm{M}$, Lee $\mathrm{T}$, et al. Sustained dysregulation of the plasma renin-angiotensin system in acute COVID-19. Res Square 2021; pre-print [https://doi.org/10.21203/rs.3.rs-125380/v1].

14 Patel SK, Juno JA, Lee WS, et al. Plasma ACE2 activity is persistently elevated following SARS-CoV-2 infection: implications for COVID-19 pathogenesis and consequences. Eur Respir J 2021; 57: 2003730. 